\section{Pelvic posterior compartment defects: comparative study of two vaginal surgical procedures}

\author{
Vito Leanza, Eva Intagliata, \\ Gianluca Leanza, Rosario Vecchio \\ Department of Surgery, University \\ of Catania, Italy
}

\section{Abstract}

This study was undertaken to compare two surgical techniques for rectocele repair. Between January 2005 and December 2010, 180 patients with III grade symptomatic rectocele were enrolled in this alternative prospective randomized study. 90 patients (group A) were treated with perineal body anchorage of posterior septum, and 90 (group B) with the traditional Denonvilliers' transversal suture. Pre- and post-operative data, including Ap and Bp values, recurrence rates and quality of life was assessed. The mean follow-up was 22 months (range 9-72 months). For statistical purpose, Student's $t$ test, chi-square test and logistic regression analysis were evaluated. Post-operatively, in group A Ap and Bp value were respectively $-2.0 \pm 1.0$ and $-2.5 \pm 0.5$ $(\mathrm{P}<0.001$ for both values). In group $\mathrm{B}, \mathrm{Ap}$ and $\mathrm{Bp}$ value were respectively $-1.9 \pm 2.1$ and $-2.1 \pm 0.9$ ( $\mathrm{P}<0.001$ for both values). A total of 81 (93.1\%) patients in group A and 76 (86.3\%) in group $\mathrm{B}$ reported improvement in symptoms $(\mathrm{P}=0.222)$ after surgery. Recurrence rates were $5(5.7 \%)$ and $6(6.8 \%)$ respectively $(\mathrm{P}=0.984)$. Quality of life improved significantly in both groups. In conclusion, both techniques are effective for the posterior compartment repair.

\section{Introduction}

Rectocele is defined as a herniation of the rectal wall inside the vagina due to a defect of the recto-vaginal septum. It is traditionally considered posterior compartment damage with weakness of posterior vaginal wall support resulting in a bulging of the rectum into the vaginal cavity. It is sometimes associated with central or anterior defect. ${ }^{1}$. One of the main causes of rectal prolapse is the operative vaginal birth, but the evidence of the defect occurs after many years ${ }^{1}$ Other possible causes are chronic increase in abdominal pressure (constipation, straining), prolonged bipedal posture, and congenital or inherited weakness in the pelvic support system. Symptoms of a rectocele include bearing down sensation and vaginal fullness or heaviness. Among functional troubles, constipation or sensation of incomplete emptying of the rectum with bowel movement ought to be considered. When the prolapse is severe, the patient must place one or two fingers inside the vagina in order to give ease the defecation.

The treatment of rectocele is surgical, and the approach can be transperineal, ${ }^{2,3}$ transanal, ${ }^{2,4-6}$ transvaginal $^{2,7}$ and, in selected cases, trans-abdominal.

The transanal procedures are the SullivanKhubchandani technique, the stapled transanal rectal resection (STARR), and the trans-STARR technique. The main transvaginal techniques are the perineal body anchorage (PBA) to the posterior septum and the traditional Denonvilliers' transversal suture after removing of the vaginal skin. The transabdominal and transperineal techniques are mainly performed for true rectal prolapse. The transperineal techniques are the Alteimer's rectosigmoidectomy and the Delorme's surgical procedure. The abdominal approaches consist of open or laparoscopic techniques, the latter offering significant advantages compared to traditional surgery. ${ }^{8-10}$

In this study we compare the results of the two above mentioned transvaginal surgical techniques. Rectal symptoms, dyspareunia, quality of life, recurrence rate and post-operative complications have been considered.

\section{Materials and Methods}

A total of 180 patients with III grade symptomatic rectocele, were enrolled in an alternative prospective randomized study from January 2005 to December 2010. After clinical evaluation, patients were allocated to 2 treatment groups, formed by 90 patients each. A total of 90 patients (group A) were treated with perineal body anchorage of posterior septum, and 90 (group B) with the traditional Denonvilliers' transversal suture. The preoperative symptoms and findings were similar between both groups (Table 1). Randomization was done assigning alternatively patients to each group after clinical evaluation. This modality of patients' selection was retained more suitable for clinical practice. Once a patient with these complaints was admitted to hospital, a very detailed diagnostic work-up was necessary. On physical examination, a rectocele was revealed by the descent of posterior vaginal wall while the patient performed the Valsalva's maneuver. Confirmation of the defect was afforded by placing one finger into the rectum and one into the vagina to verify the alteration of the recto-vaginal septum.
Correspondence: Eva Intagliata, Casella postale 226, 96011 Augusta, Italy.

Tel: +39.347.0674195 - Fax: +39.095 .7435289 .

E-mail: evaintagliata@vodafone.it

Key words: rectocele, posterior compartment, prolapse.

Received for publication: 13 June 2013.

Revision received: 16 September 2013.

Accepted for publication: 17 September 2013.

This work is licensed under a Creative Commons Attribution NonCommercial 3.0 License (CC BYNC 3.0).

(C) Copyright V. Leanza et al., 2013

Licensee PAGEPress, Italy

Urogynaecologia 2013; 27:e5

doi:10.4081/uij.2013.e5

Preoperative defecography was done in 56 group A and in 53 group B patients who complained constipation, in order to exclude other pathologies. Occult intussusceptions, nonrelaxing puborectalis syndrome and previous rectocele repair, were excluded.

\section{Perineal body anchorage technique}

The patient was placed in a dorsal lithotomy position. A transverse incision was made at the muco-cutaneous junction and thereafter the posterior vaginal wall was opened under the mucosa transversally in all the extent of bulge. The rectal wall and recto-vaginal connective tissue were separated from the vaginal wall by both sharp and blunt dissection, avoiding rectal injury. If an enterocele sac was shown, it was dissected, opened, and closed with a tobacco bag suture. Then the recto-vaginal fascia was sutured with the perineal body using separated delayed absorbable stitches. The perineorrhaphy was performed with one or two horizontal sutures. Excess vaginal mucosa was then excised, aiming at a two or three finger width vaginal caliber and the vaginal wall was closed with running delayed absorbable sutures (Figure 1A). Mean operative time was 20 min (range 10-40).

\section{Traditional Denonvilliers' transver-}

\section{sal suture technique}

The patient was placed in a dorsal lithotomy position. A transverse incision was made at the muco-cutaneous junction and thereafter the posterior vaginal wall was incised at the midline. The rectal wall and recto-vaginal connective tissue were separated from the vaginal wall by both sharp and blunt dissection. If an enterocele sac was present, it was repaired as well. At this point, in spite of the previous technique, the Denonvilliers' recto-vaginal fascia was linked at the midline with interrupted 
delayed absorbable sutures. Longitudinal suture of the posterior vaginal skin after removing the redundant tissue, was performed (Figure 1B). Mean operative time was $25 \mathrm{~min}$ (range 10-45).

Questions concerning sexual life covered also frequency of vaginal intercourses, dyspareunia, and the effect of rectocele operation on quality of sexuality.

\section{Results}

Comparison between the two groups' data was performed with Student's $t$ test for independent samples. Proportions were compared with chi-square test $\left(\chi^{2}\right)$. A logistic regression analysis was performed to control for covariates that differed in our two groups despite randomization. The quality of life was assessed by specific (pelvic floor distress inventory, pelvic floor impact questionnaire, Wexner score, sexuality score) and aspecific tests [locus of control of behaviour, visual analog scale (VAS) score]. Pelvic organs prolapse quantification (POP-Q) was used for evaluation of prolapse, as recommended by the International Continence Society, which are employed by gynecologists to describe pelvic organ status in patients suffering from pelvic organ prolapse. ${ }^{11,12}$ Measurement of the location of Ap point, which is located at the posterior vaginal wall $3 \mathrm{~cm}$ proximally from the hymeneal ring, is the method used to estimate the presence of rectocele. All the patients suffered from pelvic heaviness (100\%), bearingdown sensation (100\%), vaginal bulge (100\%), and difficulties in rectal emptying (100\%). Need to digitally assist rectal emptying was reported by 56 patients in group A (62.2\%) and in 53 patients in group B (59\%). According to POP-Q score, Ap value was $2.2 \pm 1.8$ and $\mathrm{Bp}$ value was $4.9 \pm 2.3$ in group $A$. Ap value was $2.3 \pm 1.7$ and $B p$ value was $4.8 \pm 2.1$ in group $B$.

There were 5 drop-outs from follow-up, among them 3 in the former and 2 in the latter group. The follow-up mean time was 22 months (range 9-72 months). Follow-up was always performed by a team of at least two Authors (LV and LG) through clinical and instrumental examinations [ defecography and transrectal ultrasonography (TRUS) when required]. Self-assessment questionnaires were administered to each patient.

At the follow-up, in group A Ap value was $-2.0 \pm 1.0$ (Student's $t$ test $=19.11 ; \mathrm{P}<0.001$ ) and Bp value was $-2.5 \pm 0.5$ (student's $t$ test $=29.49$; $\mathrm{P}<0.001$ ). In group $\mathrm{B}, \mathrm{Ap}$ value was $-1.9 \pm 2.1$ (Student's $t$ test $=14.53 ; \mathrm{P}<0.001$ ) and Bp value was $-2.1 \pm 0.9 \quad$ (Student's $t$ test $=28.31$; $\mathrm{P}<0.001)$. Table 2 summarizes the pre-operative and post-operative POP-Q scores.

A total of 81 (93.1\%) patients in group A and
$76(86.3 \%)$ in group B reported improvement in rectal symptoms $(\mathrm{P}=0.222)$. Need to digitally assisted rectal emptying decreased significantly in both groups, up to 4 (4.6\%) in group A and 3 (3.4\%) in group B.

A total of 70 women in group A (80.46\%) and 72 in B group (81.82\%) were sexually active; $63 / 70$ (90\%) in group A and 64/72 (88.9\%) in group $\mathrm{B}$ reported improvement in their sexual activity $\left(\mathrm{X}^{2}=0.04 ; \mathrm{P}=0.838\right) .2 / 70 \quad(2.85 \%)$ patients in group A and 1/72 (1.38\%) patient in

group B had persistent dyspareunia. One patient in group B reported de novo dyspareunia. No patients reported incontinence of liquid or solid stool. The recurrence rate of rectocele was $5(5.7 \%)$ in group A and $6(6.8 \%)$ in group $\mathrm{B}(\mathrm{P}=0.984)$ (Table 3). Post-operative statistical comparison of the results of the two groups showed a not-significant difference $(\mathrm{P}>0.001)$. Defecography (made in 50 patients of group A and in 47 among of group B) showed a significant decrease in rectocele

Table 1. Pre-operative patients' data operated on for rectocele.

\begin{tabular}{lcc} 
& PBA $(\mathrm{n}=90)$ & TDIS $(\mathrm{n}=90)$ \\
Mean age (years) & 62 & 59 \\
Postmenopausal years (mean) & 9.5 & 8.6 \\
\hline Mean body mass index $\left(\mathrm{kg} / \mathrm{m}^{2}\right)$ & 27.6 & 27.8 \\
Previous hysterectomy & 6 & 5 \\
\hline Mean duration of symptoms (months) & 20 & 22 \\
Pre-operative digitally assist rectal emptying & 56 & 53 \\
\hline Pre-operative dyspareunia & 70 & 72 \\
\hline
\end{tabular}

PBA, perineal body anchorage; TDTS, traditional Denonvilliers' transversal suture.

Table 2. Pre-operative and post-operative pelvic organs prolapse quantification value in perineal body anchorage versus traditional Denonvilliers' transversal suture.

$\begin{array}{lccc}\text { POP-Q value } & \text { Pre-0perative } & \text { Post-0perative } & \text { Statistics } \\ \text { (PBA) Ap } & 2.2 \pm 1.8 & -2.0 \pm 1.0 & \mathrm{t} \text { Stud. }=19.11 \\ \mathrm{P}<0.001 & \mathrm{t} \text { Stud. }=29.49 \\ \mathrm{P}<0.001 \\ \text { (PBA) Bp } & 4.9 \pm 2.3 & -2.5 \pm 0.5 & \mathrm{t} \mathrm{Stud.}=14.53 \\ & & & \mathrm{P}<0.001 \\ \text { (TDTS) Ap } & 2.3 \pm 1.7 & -1.9 \pm 2.1 & \mathrm{t} \text { Stud. }=28.31 \\ \text { (TDTS) Bp } & 4.8 \pm 2.1 & -2.1 \pm 0.9 & \mathrm{P}<0.001\end{array}$

POP-Q, pelvic organs prolapse quantification; PBA, perineal body anchorage; $t$ Stud., Student's $t$ test; TDTS, traditional Denonvilliers' transversal suture.

Table 3. Post-operative patients' data operated on for rectocele.

\begin{tabular}{lcc} 
& Group A $(\mathrm{n}=87)$ & Group B $(\mathrm{n}=88)$ \\
Drop-out & 3 & 2 \\
Improvement of rectal symptoms & 81 & 76 \\
\hline Post-operative digitally assist rectal emptying & 4 & 3 \\
Post-operative dyspareunia & $2 / 70$ & $1 / 72$ \\
\hline Recurrence rate of rectocele & 5 & 6 \\
\hline
\end{tabular}

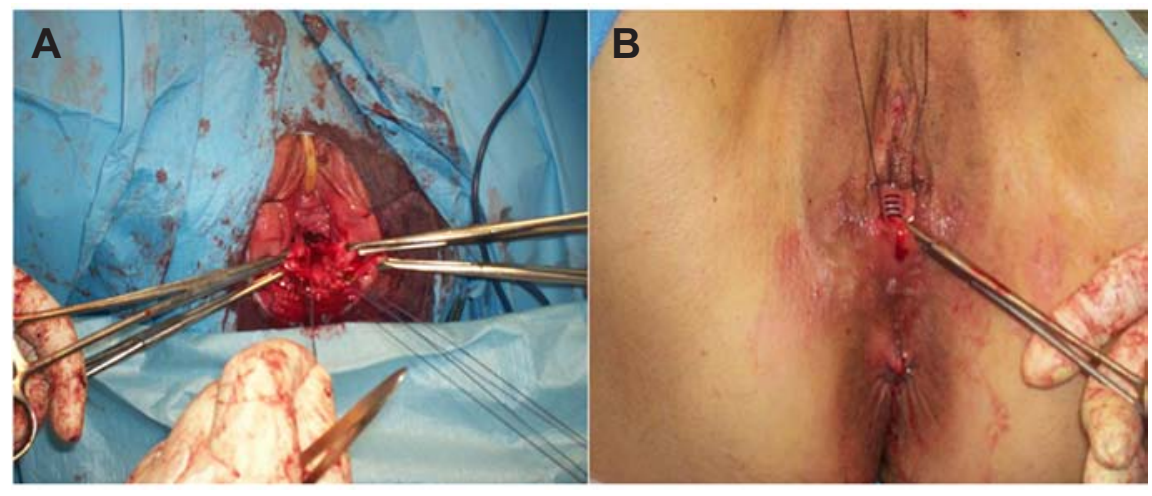

Figure 1. A) Perineal body anchorage; B) traditional Denonvilliers' transversal suture. 
depth in both groups. Mean hospital stay was 4 (range 3-6) and 4,2 (range 3-7) days in groups $A$ and $B$ respectively. We found significant difference in VAS scores, in the majority of the main domains of King's health Questionnaire and in the other questionnaires regarding preoperative and post-operative data $(\mathrm{P}<0.001)$, whereas the results of both procedures were comparable $(\mathrm{P}>0.001)$. Subject satisfaction was not significantly different between group $\mathrm{A}$ and $\mathrm{B}(\mathrm{P}>0.001)$.

\section{Discussion}

One of the main causes of rectal prolapse is the operative vaginal birth, but the evidence of the defect occurs after many years..$^{13}$ Other possible causes are chronic increase in abdominal pressure (constipation, straining), bipedal posture, or congenital or inherited weakness in the pelvic support system. The objective diagnosis of rectocele is most commonly made by the gynecologists and the general surgeons. Pelvic exam may reveal a tissue bulging into the posterior compartment of the vagina. Digital rectal exam is useful to evaluate the posterior vaginal wall weakness and the defect at the anterior wall of the rectum. Defecography is a useful imaging modality since it can detect the presence of a rectocele, quantify its size and the degree of rectal emptying as well as identify a non-relaxing pubo-rectalis muscle and assess the rectal empting capacity. When constipation is the main symptom without prolapse, manometry, TRUS and pudendal nerve terminal motor latency should be considered.

Conservative management is almost always attempted before surgical repair. ${ }^{14}$ The surgical indication to rectocele repair is controversial, but most surgeons advocate it when a rectocele is symptomatic and of large dimension $(>3 \mathrm{~cm})$, or if the rectum fails to empty sufficiently on defecography. ${ }^{15}$ Sometimes associated repair of anterior and central compartments is required. ${ }^{16-19}$

Although a lot of Authors have reported satisfactory anatomic results, conflicting results on bowel and sexual function have been observed after transvaginal approaches. The major concern regarding the adverse effects of the vaginal approaches is functional alteration. ${ }^{14,20-22}$ In the present study one patient in group A presented de novo dyspareunia, but $90 \%$ in group $\mathrm{A}$ and $88.9 \%$ in group B experienced improvement in sexual activity. These previous reports prompted us to pay attention to avoid dyspareunia after rectocele repair; modulation of the caliber of the vaginal opening is a right key to prevent this complication.

Kahn et al. ${ }^{14}$ reported that a pre-operative percentage of sexual dysfunction is raised from $18 \%$ to $27 \%$ in their follow-up of 171 patients treated by vaginal approach, and Paraiso et $a l^{20}$ noted a $12 \%$ post-operative dyspareunia rate. An improvement in symptoms related to defecation was noted in both groups, and it is reported in the literature ranging from 70 to $95 \%{ }^{11,23,24}$ When compared with the pre-operative situation, the need to digitally assist rectal emptying was statistically significantly reduced in both groups after surgery. These improvements are comparable to those reported by other Authors, ranging from 3 to $7 \%$.11,20-22 Objective measurement at defecography during the follow-up showed a significant decrease in rectocele depth in both groups. PBA is more valid for reducing the bulking and maintaining a better anatomic result with time.

The recurrence rate of rectocele ranges from 5.7 to $7 \%$ after the transvaginal techniques in the literature. ${ }^{11}$ Complications as rectal stenosis with constipation, anal incontinence, risk of infection, recto-vaginal fistula, fecal urgency, incontinence to flatus or feces, infection and rectovaginal fistula have not been reported in the Literature after transvaginal surgery. Both transvaginal surgical techniques above described, are effective to solve anatomic posterior compartment defect and to improve the functional symptoms.

\section{References}

1. Leanza V, Accardi M, Dati S, et al. Correlation between pelvic support and delivery. Urogyn Int J 2007;21:188-92.

2. Rosen Ada. Obstructed defecation syndrome: diagnosis and therapeutic options, with special focus on the STARR procedure. IMAJ 2010;12:104-6.

3. Van Laarhoven CJ, Kamm MA, Bartram CI, et al. Relationship between anatomic and symptomatic long-term results after rectocele repair for impaired defecation. Dis Colon Rectum 1999;42:204-11.

4. Block JR. Transrectal repair of rectocele using obliterative suture. Dis Colon Rectum 1986;29:707-11.

5. Khubchandani IT, Sheets JA, Stasik JJ, Hakki AR. Endorectal repair of rectocele. Dis Colon Rectum 1983;26:792-6.

6. Sehapayak S. Transrectal repair of rectocele: an extended armamentarium of colorectal surgeons. A report of 335 cases. Dis Colon Rectum 1985;28:422-33.

7. Porter WE, Steele A, Walsh P, et al. The anatomic and functional outcomes of defect-specific rectocele repairs. Am J Obstet Gynecol 1999;181:1353-8.

8. Vecchio R, Marchese S, Intagliata E, et al. Long-term results after splenectomy in adult idiopathic thrombocytopenic purpura: comparison between open and laparoscopic procedures. J Laparoendosc Adv Surg Tech
2013;23:192-8.

9. Vecchio R, Cacciola E, Martino M, et al. Modifications of coagulation and fibrinolytic parameters in laparoscopic cholecystectomy. Surg Endosc 2003;17:428-33.

10. Vecchio R, MacFadyen BV. Laparoscopic common bile duct exploration. Langenbecks Arch Surg 2002;387:45-54.

11. Nieminem $K$, Hiltunen $R$, Laitinen $J$, et al. Transanal or vaginal approach to rectocele repair: a prospective, randomized pilot study. Dis Colon Rectum 2004;47:1636.

12. Bump RC, Mattiasson A, Bø K, et al. The standardization of terminology of female pelvic organ prolapse and pelvic floor dysfunction. Am J Obstet Gynecol 1996;175:10-7.

13. Leanza V, Accardi M, Dati $S$, et al. Correlations between pelvic support and delivery. Proceedings of the 17th AIUG National Congress, 2007 May-Aug, Genoa, Italy. UIJ 2007;21 suppl 2:188-92.

14. Kahn MA, Stanton SL. Posterior colporrhaphy: its effects on bowel and sexual function. Br J Obstet Gynaecol 1997;104:82-6.

15. Samuelsson E, Victor A, Svardsudd K. Determinants of urinary incontinence in a population of young and middle-aged women. Acta Obstet Gynecol Scand 2000;79:208-15.

16. Leanza V. Tension-free mini-invasive antiincontinence procedures: comparison among three main pathways. Open Women Health J 2012;6:30-5.

17. Gasbarro N, Leanza V. Uterine and vaginal suspension in uterovaginal prolapsed from the tendineous arch of the levator ani muscle (proposal of a new technique). Giorn Ital Ostetr Ginecol 2009;31:469-72.

18. Leanza V, Dati S. Central compartment prolapse: what is the best route? Proceedings of the 19th AIUG National Congress, 2009 MayAug, Naples, Italy. UIJ 2009;23 suppl 2:117-22.

19. Leanza V, Cassaro N, Di Prima F. Hydronephrosis and vault prolapse. Proceedings of the 19th AIUG National Congress, 2009 May-Aug, Naples, Italy. UIJ 2009;23 suppl 2:129-32.

20. Paraiso MF, Weber AM, Walters MD, Ballard LA, Piedmonte MR, Skibinski C. Anatomic and functional outcome after posterior colporrhaphy. J Pelvic Surg 2001;7:335-9.

21. Mellgren A, Anzen B, Nilsson BY, et al. Results of rectocele repair; a prospective study. Dis Colon Rectum 1995;38:7-13.

22. Lopez A, Anzen B, Bremmer S, et al. Durability of success after rectocele repair. Int Urogynecol J 2001;12:97-103.

23. Kudish BI, Iglesia CB. Posterior wall prolapse and repair. Clin Obstet Gynecol 2010;53:5971.

24. Schwandner T, Roblick MH, Hecker A, et al. Transvaginal rectal repair: a new treatment option for symptomatic rectocele? Int J Colorectal Dis 2009;24:1429-34. 